\title{
Discussion on the Application of PPP Model in New Infrastructure Construction
}

\author{
Lei Cheng ${ }^{1,2}$ \\ ${ }^{1}$ Postdoctoral Workstation of China Construction Bank, Beijing, China \\ ${ }^{2}$ Postdoctoral Research Station of Tsinghua University of China, Beijing, China \\ Email: absorb123@126.com
}

How to cite this paper: Cheng, L. (2019) Discussion on the Application of PPP Model in New Infrastructure Construction. Open Journal of Social Sciences, 7, 283-288. https://doi.org/10.4236/jss.2019.79022

Received: August 21, 2019

Accepted: September 24, 2019

Published: September 27, 2019

Copyright $\odot 2019$ by author(s) and Scientific Research Publishing Inc. This work is licensed under the Creative Commons Attribution International License (CC BY 4.0).

http://creativecommons.org/licenses/by/4.0/

\begin{abstract}
In order to study how to promote the new infrastructure construction by PPP model, this paper summarizes the meaning and characteristics of Public-Private Partnership, elaborates the significance of PPP model applied in new infrastructure, and expounds the problems faced by PPP model applied in new infrastructure. The paper shows that if we overcome the difficulties for the PPP model, the PPP model can promote the new infrastructure construction. And the paper gives some suggestions: changing the traditional role played by the government, highlighting its guiding function, formulating rational distribution of interests, resolving dispute reasonably, forming scientific and rational pricing mechanism for the public good and service, cultivating specialized personnel.
\end{abstract}

\section{Keywords}

PPP, New Infrastructure, Social Capitalist, Local Government Debt Pressure

\section{Introduction}

At the end of 2018, the National Annual Economic Conference was held in Beijing. The conference defined " $5 \mathrm{G}$, artificial intelligence, industrial internet, EPC network" as "New Infrastructure Construction", and put forward speeding up the construction of new infrastructure. The construction of new infrastructure spends too much time, lots of money and needs powerful technological capability, so capital and technology should be considered simultaneously. Now, the internet enterprises such as Baidu, Alibaba, Tencent have acquired leading advantages in the field of 5G, artificial intelligence, industrial internet, EPC network, but they focused only on the technological application. In order to realize the 
sustainable development of high technology, we should strengthen new infrastructure, provide suitable environment for the diffusion of new knowledge and new technology.

Since 2014, Public-Private Partnership model had been applied in traditional infrastructure. And we have made great achievements, accumulated abundant experiences from it. It is significant to study how to extend the experiences to new infrastructure construction. So this paper helps us understand the nature of the Public-Private Partnership model and learn from experiences, then better improve the quality and efficiency of new infrastructure.

Scholars have different views about the PPP model. Some emphasize the cooperation between public sector and private sector, Yuan (2018) represents if public sector and private sector want to cooperate with each other in harmony, they should clarify respective obligations and rights [1]. Jiang (2018) says public sector and private sector reach a deal through certain media, then complete the task together [2]. Some view the PPP model from the public perspective. Ma (2017) thinks the PPP model's aim is to reduce the government's financial burden and accelerate the construction of local urban infrastructure projects [3]. Xun (2018) points out the PPP model promotes the government to transform its duty from controlling the market to participate in the market [4]. Some view the PPP model from the private capital perspective. Li (2018) proposes we should explore the connotation of private capital, draw on the successful experiences from foreign PPP Model, and establish a fair, transparent and effective mechanism for selecting private capital parties [5]. Li (2018) indicates the private capital should take the responsibility of construction funds in highway project, so it is necessary to make comprehensive analysis on social capital [6]. Other scholars view PPP model from the perspective of risk. Jiang (2018) represents the government is supposed to improve the legal system, avoiding financial risks [7]. Zhou (2017) thinks the risk mainly comes from four aspects: policy, finance, technology and operation [8].

\section{Meaning and Characteristics of Public-Private Partnership}

Public-Private Partnership is a new model in which public sector establish cooperative relationships with private sector, to provide public good and service. Sun (2017) says that PPP mode is shaped by benefit sharing and risk sharing, which makes full use of the advantages of both sides to improve the quality and efficiency of the supply of public goods or services, through the introduction of market competition mechanism as well as the incentive and restraint mechanism [9].

Firstly, establish the partnership. Government and private sector establish equal and cooperative relationship, which is different from principal-agent or administrative relationship. Both sides form a new group to achieve the common goal. 
Secondly, share the revenue. Most of PPP projects are non-profitable. Government and private sector cooperate with each other, following the principle of benefit-sharing.

Thirdly, share risk together. According to market principles, Any PPP project has the possibility of investments failing, but if the government and private sector establish equal and cooperative relationship, they have to undertake risk commonly, sharing the income. In detail, they could negotiate risk ratio, risk assume and risk prevention measure with each other.

\section{The Significance of PPP Mode Applied in New Infrastructure Construction}

\subsection{Can Fully Inspire the Social Capitalist's Enthusiasm and Creativity to Participate in New Infrastructure}

The difference between new infrastructure and traditional infrastructure is that, the latter is capital-intensive industry related to highways, railways and bridges, but the former is capital-intensive and technology-intensive industry with high $R \& D$ investment. Nowadays, the enterprises engaged in " $5 \mathrm{G}$, artificial intelligence, industrial internet, EPC network" characterized by asset-light, high-tech, high-growth. Some enterprises are so-called Unicorn with absolutely competitive advantage. The investment and construction period for new infrastructure is much longger than trational infrastructure, but after it is put into use, it will produce enormous economic benefits. The powerful profit can arouse social capitalist's initiative to support new infrastructure.

\subsection{Can Control Public Expenditure Effectively, Release the Local Government Debt Pressure}

New infrastructure which needs huge capital input, it will bring greater financial pressure to the government. Nowadays the whole country's macro-leverage ratio has approached $250 \%$, it is extremely urgent to control local government debt. In fact, regulatory authorities are increasingly scrutinizing the scale and purpuse of local government's debt, it is difficult for local government to support new infrastructure by issuing debts. If attracting social capitalist to support the infrastructure, it can save government's capital, and alleviates government's debt pressure.

\subsection{Can Lead Social Capital to Rational Field, Allocate Social Resources Effectively}

In recent years, private investment declining increasingly, reflects that socio-economic development faces greater pressure. New infrastructure which represents the direction of China's economic development, will have tremendous impact on human life and social progress. PPP model can realize the optimal allocation of social resources, preventing social capital from flowing to outdated capacity field. 


\subsection{Can Improve the Operation and Management Ability of New Infrastructure}

Traditional PPP model operates by acquiring franchise, which contains charging right and income right of asset. In the actual operation process, charging right and income right of asset have non business with technology. But the construction and maintainment of new infrastructure should conform technology standard, so PPP model applied in new infrastructure can improve the operation and management ability of new infrastructure.

\section{The Problems Faced by PPP Model Applied in New Infrastructure}

\subsection{Strong Government May Divorce the PPP Model from the Actual Needs of the Market}

In the traditional PPP model, because of government owns the rights to program, buget, approve and etc, the government played the powerful role, the social capitalist play the role of cooperation and support. However, the PPP model applied in new infrastructure has distinctive features with higher technical standards. So in the cooperation relationship of PPP model, social capitalist is more important than government. If the government behaves like a bully, the cooperation relationship may be destroyed.

\subsection{The Unclear Mechanism of Benefit Distribution May Restrict the Social Capitalist's Enthusiasm}

Benefit distribution is the core item in PPP model, especially in new infrastructure. Most traditional infrastructures are public welfare projects, income comes from government's subsidies, so the calculation of project's cash flow is accurate. However, the new infrastructure relies on commercial operation. Revenue may exceed expectation, or can't cover cost. If there is no clear benefit distribution mechanism between the government and social capitalist, the social capitalist may be quit from the cooperation.

\subsection{The Long Period of PPP Model Contract May Cause Much Uncertain}

Tradition infrastructure which refers to fixed buildings, which will not change according to time and space. But with modern science and technology upgrading, new infrastructure could be updated. We cannot forecast changes in decades, so if the cooperative period is too long, the uncertain may destroy the relationship between the government and social capitalist.

For example, the legal system of PPP model in China is not perfect enough, so it will be adjusted and changed in the future, as PPP model develops and changes continuously. That may lead to changes in project legitimacy, cooperation mode and benefit distribution mode, policy changes and adjustments may lead to project failure., In addition, great changes will take place in domestic 
economic structure and international political and economic situation in the future, which leads to financial risks related to interest rate and exchange rate.

\subsection{The Cost of Public Good and Service May Be Increased by Private Sector}

New infrastructure belongs to Quasi-Public good and service. If government provides public good and service exclusively, it can decrease the cost of the public good and service by extending the recovery cycle, or by providing governmental financial subsidies. But if private sector involved in PPP model, it has to consider how long can recover the cost of new infrastructure, for the private sector is profit-oriented.

\section{The Suggestions on the PPP Model Applied in New Infrastructure}

\subsection{Change the Traditional Role Played by the Government, Highlight Its Guiding Function}

The government plays traditional role by providing public service, whereas the social capitalist is producer and operator of public service. Owing to new infrastructure acquires technological standard and parameter, the government which lacked related experiences, don't have ability to operate and manipulate. So it is necessary to adjust the traditional role played by the government, the government should guide the social capitalist to be responsible for the new infrastructure management, construction and maintenance.

\subsection{Formulate Rational Distribution of Interests}

PPP model involves multiple interests, benefit distribution is the key factor for PPP model applied in new infrastructure. In the PPP model, the government and social capitalist should distinguish respective responsibility and role. Social capitalist wishes to maximize the profit, but the government prefers to minimize cost, two objectives can easily come into conflict. They should negotiate with each other, and finally reach an agreement.

\subsection{Resolve Dispute Reasonably}

During the long period, the disputes between the government and social capitalist are likely to happen. When the contradictions happened, vulnerable social capitalist is hard to safeguard their own interests. Sometimes, government clinches a deal which is beneficial for social capitalist, but after the completion of the construction, the previous agreement turns to be null and void, and the social capitalist's interests would be harmed.

\subsection{Form Scientific and Rational Pricing Mechanism for the Public Good and Service}

We should make deep analysis on the PPP model applied in new infrastructure, 
especially on the theory and practice about public good pricing. We should ensure the quality of new infrastructure, meanwhile, reduce cost of new infrastructure, so as to promote the sustainable development of new infrastructure.

\subsection{Cultivate Specialized Personnel}

On one hand, PPP model is related to multiple knowledge, such as law and finance; on the other hand, it needs independent party to make rules. So we should cultivate the talents who not only master the knowledge about law and finance, but also be familiar with concrete rule of PPP model.

\section{Conclusion}

The new infrastructure is of great significance to the upgrading of China's economic structure and the realization of high-quality economic development. The PPP model has been implemented in the field of traditional infrastructure for many years; it is the time to be extended to new infrastructure. But new infrastructure is different from the tradition infrastructure, so we cannot copy the original experiences totally. The government should strengthen the research about the PPP model, make the PPP model closely integrate with new infrastructure, so as to promote " $5 \mathrm{G}$, artificial intelligence, industrial internet, EPC network" to develop healthily and continuously.

\section{Conflicts of Interest}

The author declares no conflicts of interest regarding the publication of this paper.

\section{References}

[1] Yuan, H. (2018) Analysis of PPP Model in Municipal Infrastructure Construction. Business Culture, No. 12, 62-63.

[2] Jiang, H.P. (2018) PPP Model in Infrastructure Financing. Modern Commerce, No. $18,182-183$.

[3] Ma, Y.X. (2017) Application Prospect Analysis of PPP Model in Municipal Infrastructure. China's International Finance and Economics, No. 17, 126-127.

[4] Xun, X.W. (2018) Discussion on PPP Financing Model in Public Infrastructure. Style of Science and Technology, No. 11, 247.

[5] Li, F. (2018) Research on the Scope of Social Capital in PPP Model. New Economy, No. 11, 30-35.

[6] Li, X.G. (2018) Risk Assessment and Analysis f Social Capital Investment in Expressway PPP Project. Construction of China, No. 10, 80-81.

[7] Jiang, G.F. (2017) Study on Financial Risk Prevention of Urban Infrastructure Construction Based on PPP Model. Economy and Trade in North, No. 12, 67-68.

[8] Zhou, Y. (2017) Analysis about Financing and Risk Prevention of PPP Model from the Government's Perspective. Accounting Learning, No. 22, 212.

[9] Sun, P.P. and Ren, C. (2017) Research on PPP Mode in Ecological Governance in China. Open Journal of Social Sciences, 5, 175-187. 